\title{
Fault tolerance of asymmetrical six-phase induction machine during single open circuit fault to three open circuit faults using GUI
}

\author{
Ungku Mohamed Ismail Adrian Ungku Abdul Rahman', Wan Noraishah Wan Abdul Munim², \\ Hang Seng $\mathrm{Che}^{3}$, Mahdi Tousizadeh ${ }^{4}$, Khairul Safuan Muhammad ${ }^{5}$ \\ ${ }^{1,2,5}$ Faculty of Electrical Engineering, Universiti Teknologi MARA (UiTM), Malaysia \\ 2,3,4 UMPEDAC, University of Malaya, Kuala Lumpur, Malaysia
}

\begin{tabular}{l} 
Article Info \\
\hline Article history: \\
Received Oct 21, 2019 \\
Revised Dec 15, 2019 \\
Accepted Jan 30, 2020 \\
\hline Keywords: \\
Fault-tolerance \\
Graphical user interface \\
Six-phase machines \\
Asymmetrical induction \\
machines
\end{tabular}

machines

\begin{abstract}
The fault tolerance of multiphase drive is favourable in the industry for its reliability and safety reasons. However, from the educational point of view, the post-fault capability of six-phase machine is still unclear. This paper presents the fault tolerance of asymmetrical six-phase induction machine (A6-IM) under one to three open-circuit faults using Graphical User Interface (GUI). In this study, the capability of A6-IM has been interpreted through a simple and user-friendly GUI helping students to have a better understanding on the current limits of A6-IM. The optimization of post-fault current references is based on maximum torque (MT) and minimum loss (ML). This work provides GUI highlighting the post-fault derating of A6-IM with single isolated neutral $(1 \mathrm{~N})$ in two different modes namely MT and ML for educational purposes.
\end{abstract}

This is an open access article under the CC BY-SA license.

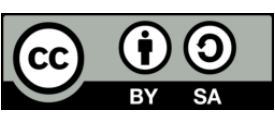

\section{Corresponding Author:}

Wan Noraishah Wan Abdul Munim, Faculty of Electrical Engineering, Universiti Teknologi MARA (UiTM), Kolej Amira Uitm Puncak Alam Road, 42300 Shah Alam, Selangor, Malaysia Email: aishahmunim@uitm.edu.my

\section{INTRODUCTION}

Graphic User Interface (GUI) benefits the computer graphics features to bridge a gap between humans and computers without getting the user to face difficulties with the programming language [1-5]. GUI can load, analyze raw data as input and the user-friendly GUI allows modification of any single parameter. Moreover, GUI able to simulate the performance of a machine and it can be extended to other applications as well [6]. Hence, GUI is a useful aid for teaching in Machines and Drives course to visualize the performance capability of machines and is more accessible to students without a background in programming.

One particular important subject in Machines and Drives is the topic machines itself. Multiphase machines have been introduced since the beginning of the 20th century [7,8]. In addition, multiphase drives have a wider degree of freedom which can be utilized for various purposes for example fault tolerance when the machine is in fault condition [9-12]. Among multiphase machines, those with a combination of three phases such as six, nine, and twelve phases are benefited from the existing three-phase machine [13, 14]. In terms of six-phase machines, there are three mainstream six-phase machines which are symmetrical (S6) with angle displacement $60^{\circ}$, asymmetrical (A6) with angle displacement $30^{\circ}$ and dual three-phase (D3) with 
angle displacement $0^{\circ}$. This paper will focus on the asymmetrical six-phase machine with single isolated neutral [13].

Single isolated neutral point improves fault-tolerant as it gives additional degree of freedom [14-17]. However, it requires additional control to regulate the zero current sequence which causes distortion to the phase currents and result in losses $[18,19]$. Thus, in the previous research literature, the post-fault for A6IM under one open-circuit fault (OCF) with single isolated neutral has provides better performance compared to two isolated neutrals $[14,20]$.

In addition, the possibilities of open-circuit fault can occur due to an open-phase fault (OPF) or open isolated bipolar transistor (IGBT) fault [21-24]. Besides that, OPF can happen where one or more phase connection(s) between the machine and converter is open-circuited or due to the fault recovery action from protective device [25-28] or poor connection issues. Therefore, in this paper, OPF will be declared as OCF.

Authors $[14,29,30]$ have investigated that for a single OCF of an asymmetrical six-phase machine, the maximum current achievable output is $69.4 \%$ for $1 \mathrm{~N}$. However, for educational purposes, there is no fault tolerance of A6-IM under 1 OCF to 3 OCFs with GUI that has been yet reported. Hence, this paper presents the post-fault capability of asymmetrical six-phase induction machine under 1OCF to 3OCFs with $1 \mathrm{~N}$ configuration in MT and ML mode operation using GUI for Machines and Drives course.

\section{RESEARCH METHOD}

In fault tolerance of A6-IM, the first stage involved healthy operation by obtaining six-phase balanced stator phase currents. For faulty operation, the optimization is performed based on different operation modes namely MT or ML using Excel "Solver". This optimization considering fault scenarios up to 3 OCFs. Next, GUI is developed to display all possible scenarios from pre-fault to post-fault using single isolated neutral as illustrated in Figure 1.

\subsection{Optimization of A6 machine using excel solver}

The implementation of fault-tolerant control is essentially divided into two stages. The first stage associates with deciding the post-fault current references. Meanwhile, the second stage will control the currents to follow its designated references. These two stages are very important in terms of fault-tolerant control.

During healthy conditions, the $x-y$ and zero sequence components are kept to zero while the machine is controlled by regulating the $\alpha-\beta$ current components. In a fault condition, the remaining healthy phase currents will be unbalanced due to the effect of the $x-y$ and zero sequence components. Therefore, the currents need to be optimized according to a different mode of operation with respect to $i_{\alpha}$ and $i_{\beta}$.

Using Excel, all the values of stator currents' angle for A6 machine from $0^{\circ}$ until $360^{\circ}$ are calculated and converted to unit radian which is known as $\theta$. It is calculated to get the value of $i_{\alpha}$ and $i_{\beta}$ is given by:

$$
\begin{aligned}
& i_{\alpha}=\cos \theta \\
& i_{\beta}=\sin \theta
\end{aligned}
$$

Then, the value of $x, y, 0+$, and 0 - currents are described in terms of $\alpha-\beta$ current reference as:

$$
\begin{aligned}
& i_{x}=k_{1} \cdot i_{\alpha}+k_{2} \cdot i_{\mathrm{B}} \\
& i_{y}=k_{2} \cdot i_{\alpha}+k_{3} \cdot i_{\mathrm{B}} \\
& i_{0+}=k_{4} \cdot i_{\alpha}+k_{5} \cdot i_{\mathrm{B}} \\
& i_{0-}=k_{7} \cdot i_{\alpha}+k_{8} \cdot i_{\mathrm{B}}
\end{aligned}
$$

While the $\alpha-\beta$ currents are set as references, the only changes will be on $K$ coefficients namely $k_{1}, k_{2}, k_{3}, k_{4}, k_{5}, k_{6}, k_{7}$ and $k_{8}$ representing for $i_{x-y}, i_{o+-0 .}$. Next step is to get the stator currents of the machine which are $I_{a 1}, I_{b 1}, I_{c 1}, I_{a 2}, I_{b 2}, I_{c 2}$ by applying inverse decoupling transformation [T6] [14].

Int J Pow Elec \& Dri Syst, Vol. 11, No. 2, June 2020 : $611-617$ 


$$
[T 6]=\frac{1}{\sqrt{3}}\left|\begin{array}{cccccc}
1 & -\frac{1}{2} & -\frac{1}{2} & \frac{\sqrt{3}}{2} & -\frac{\sqrt{3}}{2} & 0 \\
0 & \frac{\sqrt{3}}{2} & -\frac{\sqrt{3}}{2} & \frac{1}{2} & \frac{1}{2} & -1 \\
1 & -\frac{1}{2} & -\frac{1}{2} & -\frac{\sqrt{3}}{2} & \frac{\sqrt{3}}{2} & 0 \\
0 & -\frac{\sqrt{3}}{2} & \frac{\sqrt{3}}{2} & \frac{1}{2} & \frac{1}{2} & -1 \\
\frac{1}{\sqrt{2}} & \frac{1}{\sqrt{2}} & \frac{1}{\sqrt{2}} & \frac{1}{\sqrt{2}} & \frac{1}{\sqrt{2}} & \frac{1}{\sqrt{2}} \\
\frac{1}{\sqrt{2}} & \frac{1}{\sqrt{2}} & \frac{1}{\sqrt{2}} & -\frac{1}{\sqrt{2}} & -\frac{1}{\sqrt{2}} & -\frac{1}{\sqrt{2}}
\end{array}\right|
$$

There are two types of optimization used in this paper which are the minimum loss (ML) and maximum torque (MT) as defined in (4) and (5).
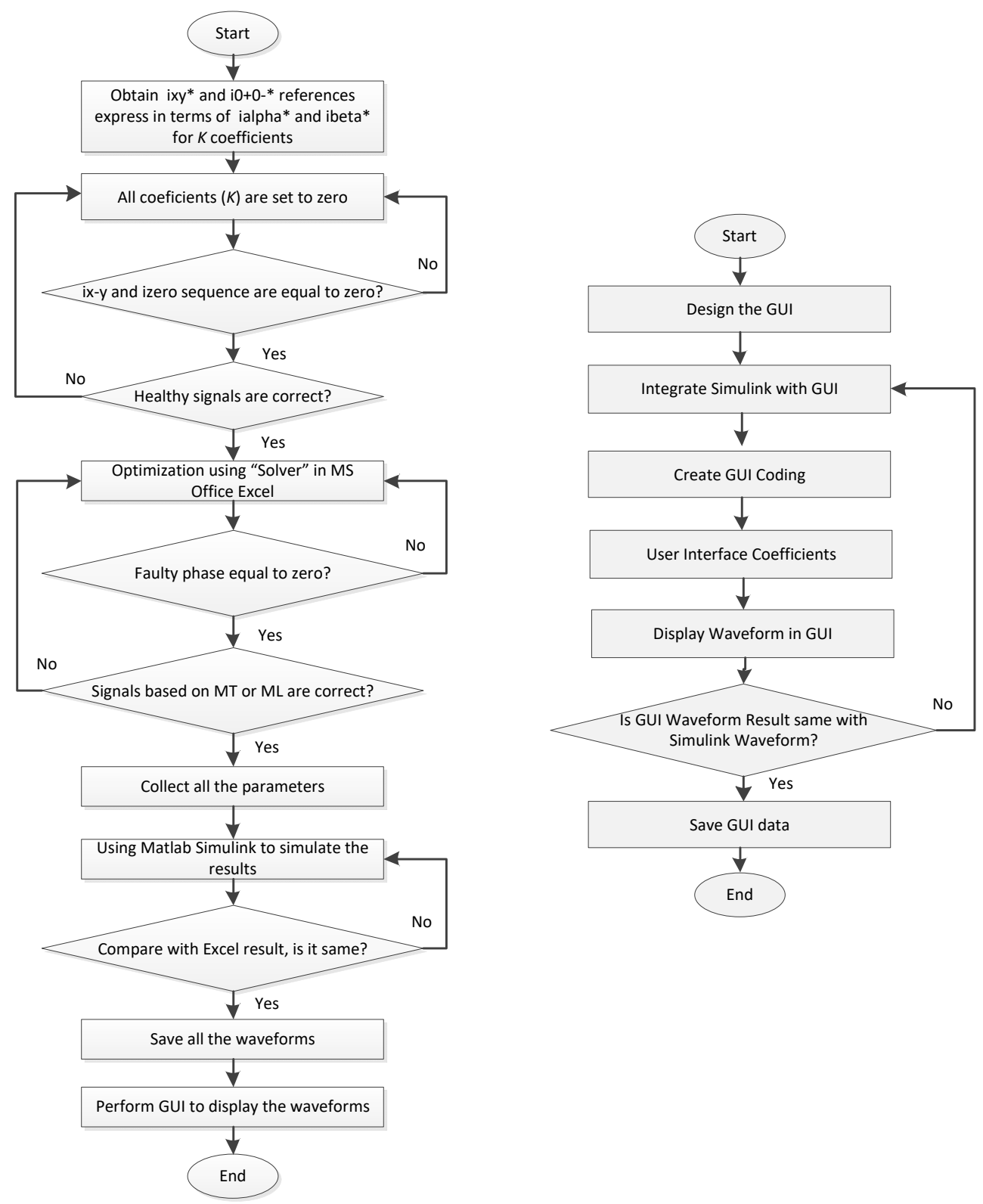

Figure 1. Optimization based on MT or ML and GUI flowchart 
ML mode: The purpose of ML is to minimize the stator copper loss defined by equation $\mathrm{A}_{\mathrm{ML}}$ [17].

$$
A_{M L}=\min \left(i_{\alpha}^{2}+i^{2}{ }_{\mathrm{B}}+i^{2}{ }_{x}+i^{2}{ }_{y}+i^{2}{ }_{0-}+i^{2}{ }_{0+}\right)
$$

However, for this mode, the maximum achievable torque is reduced and leads to uneven phase current. MT mode: For this mode, $\mathrm{A}_{\mathrm{MT}}$ aims specifically at optimizing the torque and the amplitude of the $\alpha$ $\beta$ phasor. The limitation can be seen from the higher values of stator copper losses compared to ML mode.

$$
A_{M T}=\max \left(\left|I_{\alpha \mathrm{B}}\right|\right)
$$

For single isolated neutral, zero-sequence current can flow from winding 1 to winding 2 or vice versa as given in (6). Both zero-sequence will be zero if using two isolated neutrals.

$$
I_{0+}+I_{0-}=0 .
$$

Optimization is done using MS Office Excel "Solver", an add-in that functions as a nonlinear optimization algorithm. Applying [T6 $]^{-1}$ onto the VSD currents to obtained subsequent phase currents amplitudes and the coefficients will differ for each iteration. The optimization goal is dependent on (4) and (5) for ML and MT modes respectively with constraints of (6) and the faulted phase(s) will be zero.

\subsection{Performance ondicator}

This paper has two indicators that will be able to rate the post-fault performance of the machine which is the derating factor and normalized post-fault stator copper loss.

- Derating factor $(a)$ : the value of per unit of the current phasor module postfault $\alpha-\beta$, with the restriction that the peak postfault phase current would not surpass the rated phase current [31].

$$
a=\frac{\left[I_{\alpha \mathrm{B}}\right] \cdot \text { post-fault }}{\left[I_{\alpha \mathrm{B}}\right] \cdot \text { rated }}
$$
higher.

The higher maximum torque for a given current limit can be achieved if the derating factor value is

- Normalized Post-fault Stator Copper Loss ( $\left.\mathbf{P}_{\text {loss}}\right)$ : The phase currents will be different when using the different modes, so the stator copper loss may vary. The stator copper loss, which is normalized to a healthy system, can, therefore, be determined on the basis of:

$$
P_{\text {loss }}=\frac{\left\{i_{\alpha}^{2}+i_{\mathrm{B}}^{2}+i_{x}^{2}+i_{y}^{2}+i_{0+}^{2}+i_{0-}^{2}\right\}}{i_{\alpha \cdot \text { rated }}^{2}+i_{\mathrm{B}}^{2} \cdot \text { rated }}
$$

After post-fault currents of A6-IM being optimized, the next step involves GUI. The GUI is created using MATLAB software. Using GUI application, all waveforms of currents for healthy, ML and MT located in one system to easier the user to look and analyze the waveform and data. GUI offer point-and-click navigation of software applications, mitigating the necessity for the user to study a language or type command for the application to run. MATLAB can be used to create GUIs as a front end which will then be programmed to automate actions such as tasks and calculations.

\section{RESULTS AND ANALYSIS}

Table 1 shows the overall values of derating factors, $\mathrm{P}_{\text {loss, }}$, and coefficients of the A6 induction machine under $1 \mathrm{OCF}$ to $3 \mathrm{OCF}$ with $1 \mathrm{~N}$. From Table 1, MT mode has a higher value of derating factor in all situations. At $1 \mathrm{OCF}$, MT mode produces $69.4 \%$ of derating factor while at ML mode, the value of the derating factor decreases to $54.1 \%$. 2OCFs also experience decreasing value of derating factor in the comparison of MT to ML mode which are $57.7 \%$ to $53 \%$. Both MT and ML mode for 3OCFs gives $50 \%$. Therefore, MT mode obtained more maximum torque for a given current limit compared to ML mode due to the higher derating factor.

While for the $\mathrm{P}_{\text {loss, }}$ ML mode produced lower $\mathrm{P}_{\text {loss }}$ compared to MT mode in all situations. From Table 1, under 1OCF, ML achieved 1.333 compared to MT which is 1.728. For 2OCFs scenarios, ML obtained 1.931 compared to MT which is 2 whilst for 3OCFs, both ML and MT mode achieved 2. Therefore, it can be concluded that the ML mode obtained lower copper losses for a given current limit compared to MT mode.

Int J Pow Elec \& Dri Syst, Vol. 11, No. 2, June 2020 : $611-617$ 
Simulation tests are carried out using the Simulink of MATLAB to validate the $K$ coefficients used in Table 1. Based on the information in Table 1 , the stator phase currents for the pre-fault $(t<0.02 s)$ and post-fault $(t>0.02 s)$ were plotted.

Table 1. Coefficients based on MT and ML under 1 to 3 OCFs for A6-IM

\begin{tabular}{|c|c|c|c|c|}
\hline \multirow[t]{2}{*}{ Mode } & \multirow[t]{2}{*}{ OCF (phase fault) } & \multicolumn{3}{|r|}{$1 \mathrm{~N}$} \\
\hline & & $a$ & $P_{\text {loss }}$ & Coefficients, $\boldsymbol{K}$ \\
\hline \multirow[t]{3}{*}{ MT } & 1OCF (a1) & 0.694 & 1.728 & $\begin{array}{l}\mathrm{k} 1=-0.641 \mathrm{k} 2=-0.209 \mathrm{k} 3=-0.754 \mathrm{k} 4=-0.296 \mathrm{k} 5=0 \mathrm{k} 6=0 \\
\mathrm{k} 7=-0.507 \mathrm{k} 8=0.296\end{array}$ \\
\hline & 2OCFs ( & 0.577 & 2.000 & $\mathrm{k} 1=-1 \mathrm{k} 2=0 \mathrm{k} 3=0 \mathrm{k} 4=-1 \mathrm{k} 5=0 \mathrm{k} 6=0 \mathrm{k} 7=0 \mathrm{k} 8=0$ \\
\hline & 3OCFs (al & 0.500 & 2.000 & $\mathrm{k} 1=-1 \mathrm{k} 2=0 \mathrm{k} 3=0 \mathrm{k} 4=1 \mathrm{k} 5=0 \mathrm{k} 6=0 \mathrm{k} 7=0 \mathrm{k} 8=0$ \\
\hline \multirow[t]{3}{*}{ ML } & 1OCF (a1) & 0.541 & 1.333 & $\mathrm{k} 1=-0.666 \mathrm{k} 2=0 \mathrm{k} 3=0 \mathrm{k} 4=0 \mathrm{k} 5=0 \mathrm{k} 6=0 \mathrm{k} 7=-0.471 \mathrm{k} 8=0$ \\
\hline & 2OCFs (a1, c2 & 0.530 & 1.931 & $\mathrm{k} 1=-0.815 \mathrm{k} 2=-0.044 \mathrm{k} 3=0.185 \mathrm{k} 4=-1.044 \mathrm{k} 5=0 \mathrm{k} 6=0 \mathrm{k} 7=-0$ \\
\hline & 3 OCFs $(\mathrm{a} 1, \mathrm{~b} 1, \mathrm{c} 1)$ & 0.500 & 2.000 & $\mathrm{k} 1=-1 \mathrm{k} 2=0 \mathrm{k} 3=0 \mathrm{k} 4=1 \mathrm{k} 5=0 \mathrm{k} 6=0 \mathrm{k} 7=0 \mathrm{k} 8=0$ \\
\hline
\end{tabular}

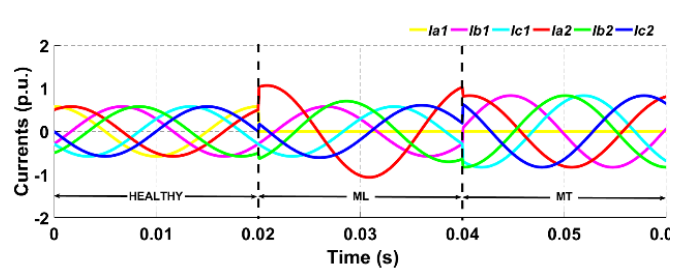

(a)

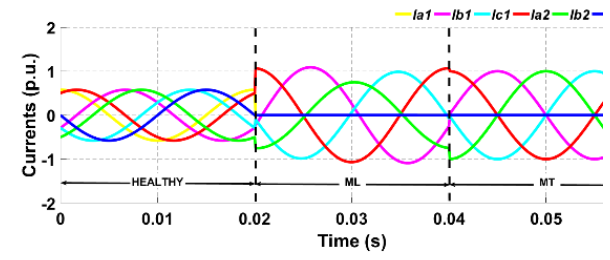

(b)

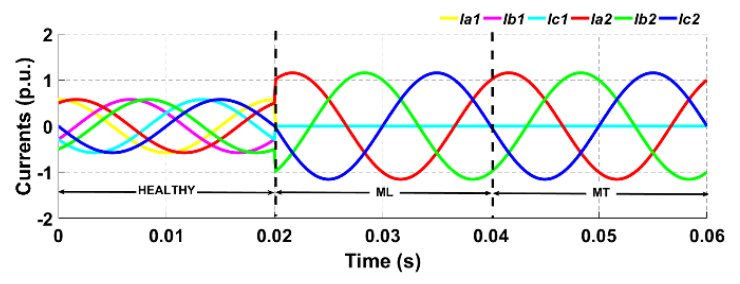

(c)

Figure 2: Stator phase currents in healthy, ML modes and MT modes for asymmetrical sixphase induction machine with single isolated neutral under (a) 1OCF, (b) 2OCFs, (c) 3OCFs

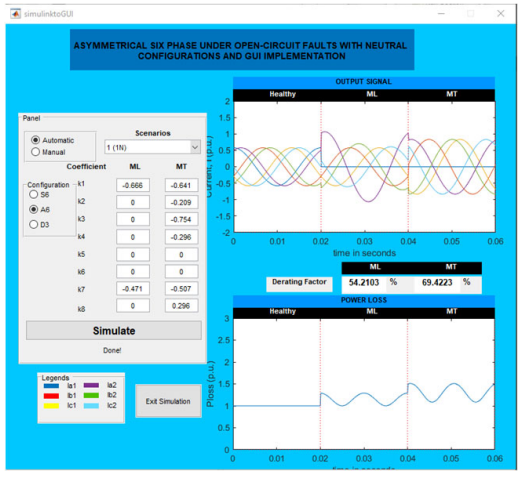

(a)

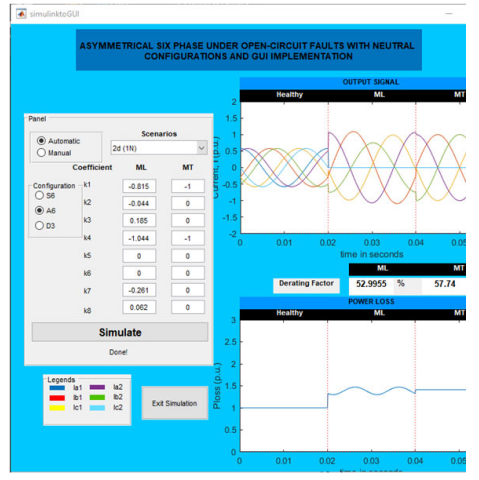

(b)

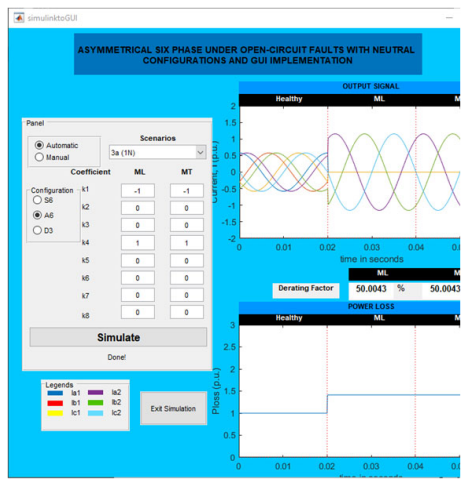

(c)

Figure 3: GUI system for asymmetrical six-phase induction machine under

(a) 1OCF, (b) 2OCFs, (c) 3OCFs 
Figure 2 shows the results for A6-IM during 1OCF, 2OCFs, and 3OCFs with single isolated neutral under healthy and post-fault condition based on ML and MT mode. In healthy condition for $t<0.02 \mathrm{~s}$, all the stator phase currents have same amplitude. After $\mathrm{t}>0.02 \mathrm{~s}$ which is in a fault condition, ML will lead to an uneven phase amplitude waveform and MT mode will give equalize amplitude of remaining healthy phase currents. As shown in Figure 3, there are three sections displayed in GUI which are healthy operation, optimization of post-fault based on MT and ML and the comparison of post-fault performance indicator showing the derating factor and stator copper losses. With this user-friendly GUI system, it will easier for the users to learn and analyze the fault tolerance capability of asymmetrical six-phase induction machines under single open circuit fault to three open-circuit faults with $1 \mathrm{~N}$. The user just needs to click the button and the result of pre- and post-fault currents will display to the user. Apart from that, this GUI helps the user to have better understanding on the operation of multiphase machine.

\section{CONCLUSION}

In this paper, an analysis of the fault-tolerant capability of six-phase asymmetrical induction machines under one open-circuit fault until three open-circuit faults with single isolated neutral has been presented. The paper presented the healthy operation, comparison of minimum loss, maximum torque, derating factor and stator copper losses under different fault scenario namely $1 \mathrm{OCF}, 2 \mathrm{OCF}$, and $3 \mathrm{OCF}$.

For fault-tolerance of A6-IM, it can be concluded that MT mode is more favorable than ML mode as the gain in torque/power is generally more significant than the increase in power losses [12]. With every additional open circuit fault, the gain in derating factor (hence torque/power) becomes more marginal. The fault scenario with 1 OCF clearly promotes the use of A6-1N. However, the machine is capable to operate in 2 OCFs and 3 OCFs. As far as the fault tolerance is concerned, the GUI is beneficial for the educator to use as an aid for teaching and learning, particularly in Machines and Drives course.

\section{ACKNOWLEDGEMENTS}

The authors would like to appreciate the aid of the Malaysian government under the project number MO013-2016 and the Universiti Teknologi MARA (UiTM) through the Malaysian Ministry of Higher Education.

\section{REFERENCES}

[1] A. Z. Bin Abdullah, M. Isa, M. N. K. H. Rohani, S. A. B. S. Jamalil, A. N. N. Abdullah, and N. Azizan, "Development of smart online partial discharge monitoring system for medium voltage power cable," International Journal of Power Electronics and Drive Systems (IJPEDS), vol. 10, no. 4, pp. 2190-2197, 2019.

[2] H. N. M. Shah, M. F. Abdollah, Z. Kamis, M. S. M. Aras, M. R. Baharon, and M. Z. A. Sallehoddin, "Develop and implementation of PC based controller for humanoid robot using digital potentiometer," Indonesian Journal of Electrical Engineering and Computer Science, vol. 15, no. 1, pp. 104-112, 2019.

[3] N. A. Salim, H. Mohamad, Z. M. Yasin, N. Fadilah, and A. Aziz, "Graphical user interface based model for transmission line performance implementation in power system," Indonesian Journal of Electrical Engineering and Computer Science, vol. 16, no. 1, pp. 92-100, 2019.

[4] N. Telagam, S. Lakshmi, and K. Nehru, "Ber analysis of concatenated levels of encoding in GFDM system using labview," Indonesian Journal of Electrical Engineering and Computer Science, vol. 14, no. 1, pp. 80-91, 2019.

[5] W. L. Martinez, "Graphical user interfaces," Wiley Interdiscip. Rev. Comput. Stat, vol. 3, no. 2, pp. 119-133, 2011.

[6] J. S. Sherfey et al., "DynaSim: A MATLAB toolbox for neural modeling and simulation," Front. Neuroinform, vol. 12, no. March, pp. 1-15, 2018.

[7] H. S. Che, E. Levi, M. Jones, W. P. Hew, and N. A. Rahim, "Current control methods for an asymmetrical six-phase induction motor drive," IEEE Trans. Power Electron, vol. 29, no. 1, pp. 407-417, 2014.

[8] D. Verma, K. B. Yadav, and P. Kumar, "Performance evaluation of asymmetrical multiphase induction motor using Matlab/Simulink," Proc. - 2016 Int. Conf. Adv. Comput. Commun. Autom. ICACCA 2016, pp. 1-6, 2016.

[9] N. K. Nguyen, F. Meinguet, E. Semail, and X. Kestelyn, "Fault-tolerant operation of an open-end winding fivephase PMSM drive with short-circuit inverter fault," IEEE Trans. Ind. Electron, vol. 63, no. 1, pp. 595-605, 2016.

[10] F. Yu, M. Cheng, K. T. Chau, and F. Li, "Control and performance evaluation of multiphase FSPM motor in lowspeed region for hybrid electric vehicles," Energies, vol. 8, no. 9, pp. 10335-10353, 2015.

[11] D. Ting, L. Fenghui, and S. Li, "Fault-tolerant method for six-phase PMSM by adjusting phase angle," 201720 th Int. Conf. Electr. Mach. Syst. ICEMS 2017, 2017.

[12] M. Rezal and D. Ishak, "Performance evaluation of multi-phase permanent magnet synchronous motor based on different winding configurations and magnetization patterns," International Journal of Power Electronics and Drive Systems (IJPEDS), vol. 10, no. 3, pp. 1197-1206, 2019.

[13] E. Levi, F. Barrero, and M. J. Duran, "Multiphase machines and drives-revisited," IEEE Trans. Ind. Electron., vol. 63, no. 1, pp. 429-432, 2016.

[14] H. S. Che, M. J. Duran, E. Levi, M. Jones, W. P. Hew, and N. A. Rahim, "Postfault operation of an asymmetrical

Int J Pow Elec \& Dri Syst, Vol. 11, No. 2, June 2020 : $611-617$ 
six-phase induction machine with single and two isolated neutral points," IEEE Trans. Power Electron, vol. 29, no. 10, pp. 5406-5416, 2014.

[15] S. N. Vukosavic, M. Jones, E. Levi, and J. Varga, "Rotor flux oriented control of a symmetrical six-phase induction machine," Electr. Power Syst. Res, vol. 75, no. 2-3, pp. 142-152, 2005.

[16] I. Gonzalez-Prieto, M. J. Duran, H. S. Che, E. Levi, M. Bermúdez, and F. Barrero, "Fault-tolerant operation of six-phase energy conversion systems with parallel machine-side converters," IEEE Trans. Power Electron, vol. 31, no. 4, pp. 3068-3079, 2016.

[17] W. N. W. A. Munim, H. S. Che, and W. P. Hew, "Fault Tolerant Capability of Symmetrical Multiphase Machines under One Open-Circuit Fault."

[18] H. S. Che, A. S. Abdel-Khalik, O. Dordevic, and E. Levi, "Parameter Estimation of Asymmetrical Six-Phase Induction Machines Using Modified Standard Tests," IEEE Trans. Ind. Electron, vol. 64, no. 8, pp. 6075-6085, 2017.

[19] M. Zabaleta, E. Levi, and M. Jones, "Modelling approaches for an asymmetrical six-phase machine," IEEE Int. Symp. Ind. Electron., vol. 2016-Novem, pp. 173-178, 2016.

[20] F. Baneira, J. Doval-Gandoy, A. G. Yepes, Ó. Ĺopez, and D. Pérez-Estévez, "Control Strategy for Multiphase Drives with Minimum Losses in the Full Torque Operation Range under Single Open-Phase Fault," IEEE Trans. Power Electron, vol. 32, no. 8, pp. 6275-6285, 2017.

[21] W. N. W. A. Munim, M. J. Duran, H. S. Che, M. Bermudez, I. Gonzalez-Prieto, and N. A. Rahim, "A Unified Analysis of the Fault Tolerance Capability in Six-Phase Induction Motor Drives," IEEE Trans. Power Electron, vol. 32, no. 10, pp. 7834-7836, 2017.

[22] H. Guzman, F. Barrero, and M. J. Duran, "IGBT-gating failure effect on a fault-tolerant predictive current-controlled five-phase induction motor drive," IEEE Trans. Ind. Electron, vol. 62, no. 1, pp. 15-20, 2015.

[23] R. K Abdul Razak, K. S Muhammad, R. Baharom, and A. M I Mamat, "Open-Circuit Fault Detection Technique for Fault-Tolerant Bridgeless Boost Rectifier," Int. J. Eng. Technol, vol. 7, no. 3.15, pp. 168, 2018.

[24] K. S. Muhammad, R. Baharom, M. K. M. Salleh, and D. D. C. Lu, "Open-circuit fault tolerant bridgeless boost rectifier," IECON Proc. Industrial Electron. Conf, pp. 2201-2206, 2016.

[25] Hyung-Min Ryu, Ji-Woong Kim, and Seung-Ki Sul, "Synchronous frame current control of multi-phase synchronous motor part II. asymmetric fault condition due to open phases," pp. 268-275, 2004.

[26] M. Tousizadeh, H. S. Che, J. Selvaraj, N. A. Rahim, and B.-T. Ooi, "Fault-Tolerant Field Oriented Control of Three-Phase Induction Motor based on Unified Feed-forward Method," IEEE Trans. Power Electron. IEEE, 2018.

[27] M. Tousizadeh, H. S. Che, J. Selvaraj, N. A. Rahim, and B. T. Ooi, "Performance Comparison of Fault-Tolerant Three-Phase Induction Motor Drives Considering Current and Voltage Limits," IEEE Trans. Ind. Electron., vol. 66, no. 4, pp. 2639-2648, 2019.

[28] W. N. W. A. Munim, M. Tousizadeh, and H. S. Che, "Effects of Zero-Sequence Transformations and Min-Max Injection on Fault-Tolerant Symmetrical Six-Phase Drives with Single Isolated Neutral," J. Power Electron, vol. 19, no. 4, pp. 968-979, 2019.

[29] A. S. Abdel-Khalik, A. M. Massoud, and S. Ahmed, "Effect of DC-Link Voltage Limitation on Postfault SteadyState Performance of Asymmetrical Six-Phase Induction Machines," IEEE Trans. Ind. Electron., vol. 65, no. 9, pp. 6890-6900, 2018.

[30] A. S. Abdel-Khalik, R. A. Hamdy, A. M. Massoud, and S. Ahmed, "Postfault control of scalar (V/f) controlled asymmetrical six-phase induction machines," IEEE Access, vol. 6, pp. 59211-59220, 2018.

[31] A. S. Abdel-Khalik, M. I. Masoud, S. Ahmed, and A. Massoud, "Calculation of derating factors based on steadystate unbalanced multiphase induction machine model under open phase(s) and optimal winding currents," Electr. Power Syst. Res, vol. 106, pp. 214-225, 2014. 